\title{
LA REBELIÓN IMPERSONAL. EL SÍSIFO DE BLANCHOT Y LA EROSIÓN DEL HOMBRE ABSURDO
}

Impersonal revolt. Blanchot's Sisyphus and the erosion of the absurd man

Noelia Billi*

Resumen

A mediados del siglo XX, Blanchot elabora una crítica minuciosa de algunos tópicos de Camus. Su interés, sobre todo, se centra en la renovación camusiana del cogito sintetizada en la fórmula Me rebelo, luego somos. Para Blanchot, el hombre desgraciado (que constituye el punto de partida del planteo del "hombre absurdo" en Camus) ha perdido el poder de decir "Yo" y, por ello, es una figura de lo impersonal que no puede ser reconducida a la persona. Sin embargo, esto no implica la renuncia a la insumisión: Blanchot recupera la figura de Sísifo para mostrar que hay una rebeldía de lo impersonal que excede al hombre, marcando así el camino a la "resistencia de lo neutro" que sería reivindicada por la filosofía francesa e italiana del siglo XXI.

Palabras clave: Blanchot, Camus, impersonal, rebelión.

Abstract

In the mid-20th century, Blanchot developed a thorough critique of some of Camus' topics. His interest mainly focused on the renewal of the camusian cogito synthesized in the formula "I rebel, therefore we are." For Blanchot, the hapless man (which constitutes the starting point for Camus' "absurd man") has lost the power to say "I" and is thus a figure of the impersonal that cannot be redirected to the person. Nevertheless, this does not entail a waiver of rebelliousness: Blanchot recovered the figure of Sisyphus to show that there is a rebellion of the impersonal that exceeds man, indicating the way to the "resistance of the neutral" to be claimed by French and Italian philosophy of the 21 st century.

Key words: Blanchot, Camus, impersonal, rebellion

\section{1. (IM)POSIBILIDAD DEL HOMBRE}

En 1953, Maurice Blanchot publica varios artículos donde recorre el itinerario de Camus en torno al absurdo a partir de las figuras de Sísifo y el "hombre rebelde", centrales para comprender el alcance de la literatura camusiana (Blanchot, 1969, p. 256-280) ${ }^{1}$. Ambos escritores parecen coincidir en el diagnóstico del presente: durante el siglo XX, el hombre alcanzó un nivel de abyección que se vio intensificado por la ausencia de consuelos ultraterrenos. En este escenario, la literatura del absurdo funcionaba como una máquina reparadora capaz de poner a lo humano de pie a partir de su rebeldía, haciendo de la lógica el bastión cuya pureza hueca funcionaba como clave de bóveda. Sin embargo, como veremos, Blanchot problematiza la "victoria

\footnotetext{
${ }^{1}$ Como es habitual en la producción de Blanchot, dichos textos fueron primero publicados como artículos consecutivos en una publicación periódica, La Nouvelle Nouvelle Revue française ( $\mathrm{N}^{\circ} 16,17$ y 18 de 1954).
} 


\section{Noelia Billi}

lógica contra el absurdo" que, según Camus, daría lugar a un cogito renovado: en vez del clásico y burgués "pienso, luego soy", el insurgente "me rebelo, luego somos". Para Blanchot, Camus hace del rebelde la contrafigura de Sísifo porque considera que su nihilismo no es capaz de sacar provecho del vacío absoluto (de moral, de principios, de naturaleza humana) a partir del cual sería posible extraer una infinitud de 'posibles' para el hombre. Blanchot eventualmente recusa esta deriva y describe el presente como región en que lo imposible constituye la esencia de lo humano, lo que supone una interpretación neutra tanto del nihilismo como del absurdo.

Como se sabe, el existencialismo fue el hilo privilegiado que anudó literatura y política durante buena parte del siglo XX francés (Sartre, 1947, 1983; Asensi Pérez, 2006; Poster, 1975; Ory y Sirinelli, 2004). De acuerdo con la paráfrasis que hace aquí Blanchot, el existencialismo (al menos el camusiano, pues con Sartre la querella toma un cariz que se relaciona más bien con la función específica de la literatura ${ }^{2}$ ) sería aquel movimiento que tiene como motor la condición "desgraciada" del hombre, su posición de sufriente extremo que no halla justificación ni consuelo en otro mundo distinto a este. Se trata entonces de una desgracia puramente humana que tiene por escenario un infierno vacío de dios (un infierno que es este mundo), donde no hay salida, ya que los que aquí permanecemos somos los auténticos condenados de la tierra. Para Blanchot, esta lucidez respecto de lo irremediable de los dolores y padecimientos constituye la constatación de la desmesura y la imposibilidad en que el hombre se encuentra ante la pérdida del mundo, y el existencialismo quedará caracterizado por responder a ello con un esfuerzo perseverante por extender, aunque sea un poco, el mundo en que el hombre es aún posible.

En el prefacio a sus Crónicas de la segunda posguerra, Camus afirmaba: "Comenzamos a salir del nihilismo" (Camus, 1953, p. 9-12), algo que celebraba, toda vez que consideraba que el nihilismo era romántico. Es que para él, ser nihilista en esas circunstancias significaba una suerte de regodeo en la impotencia. Si las luchas obreras habían demostrado algo, era que una moral era posible con el solo recurso a valores humanos, fundamentalmente, según Camus, la libertad, comprendida como la posibilidad de transformar las condiciones de existencia de cada cual en el presente. La reticencia de Blanchot ante esto no tiene que ver con la necesaria retirada del apoyo de las izquierdas de todo el mundo al régimen soviético (aunque no a la teoría social y económica marxista tout court) que era menester manifestar a viva voz cuando comenzaron a hacerse conocidas las torturas y demás vejámenes perpetrados en nombre de la "revolución"3. Antes bien, se vincula con la rehabilitación camusiana de lo absurdo ligado a "valores humanos" y a una libertad fácil de conectar a la promoción de la racionalidad que Occidente consagró como modelo de existencia de lo humano.

\footnotetext{
${ }^{2}$ Blanchot disputa con Sartre en torno a otro tópico: el de la "función" de la literatura y la posibilidad de la literatura "comprometida" (Blanchot, 1943, p. 92-101; 1949, p. 293-331).

${ }^{3}$ Esta cuestión dividió aguas en Francia y en los movimientos de izquierda de todo el mundo a mediados del siglo XX (Berstein y Milza, 1991; Winock, 2006).
} 
De acuerdo con el análisis blanchotiano, la rebeldía ético-lógica planteada por Camus solo podría conducir a la salvación si el rebelde fuera un individuo que, primero, acepta ponerse en posición de esclavo. Según esto, Blanchot desplegará una mirada nada complaciente con la posición del hombre "despojado": aquel que el siglo XX francés ha descrito recurriendo al "proletario" marxiano (el proletario que se ha quedado sin "esencia" porque no tiene nada y entonces no es ya nada), en un haz de conceptos abigarrados que va de la dialéctica amo-esclavo hegeliano-kojeviana a un Marx reinterpretado por Lenin. Refiriéndose a esta particular amalgama de lecturas que marcaron la impronta del existencialismo ateo camusiano, Blanchot explica la estrategia de rehabilitar la forma lógica del cogito cartesiano que Camus hizo célebre: "me rebelo, luego somos":

L'homme souffrant et l'homme malheureux ou soumis à la misère sont devenus étrangers aux rapports maître-esclave qui constituent, au regard de leur situation, un statut presque prometteur. L'esclave a cette chance d'avoir un maître ; le maitre est aujourd'hui ce qu'il sert, il sera demain ce contre quoi il pourra se dresser. Il y a des esclaves sans maître, dont l'esclavage est tel qu'ils ont perdu tout maître, tout rapport avec le maître, tout espoir donc d'affranchissement, comme tout possibilité de révolte. Quand le maître est perdu, parce qu'il est devenu sans nom, un pur pouvoir irresponsable, introuvable, c'est déjà une situation extrêmement difficile, mais les puissances abstraites peuvent encore être nommées, le plus lointain et le plus insaisissable s'appelle un jour Dieu, et la toute-puissance de Dieu finit par offrir prise à un combat décisif. Bien plus grave est l'esclavage qui est l'absence de l'esclave, la servitude des ombres, elle-même apparemment aussi légère qu'une ombre, là où le destin est sans poids et sans réalité. «Je me révolte, donc nous sommes », a dit Albert Camus dans une parole où il a mis toute la décision d'un espoir solidaire. Mais celui qui a perdu le pouvoir de dire «Je » est exclu de cette parole et de cet espoir (Blanchot, 1969, p. 259) ${ }^{4}$.

Sin palabra, el desgraciado no solo no puede hacerse portavoz de una lógica que le permitiría vencer el absurdo, sino que tampoco puede hacer "comunidad". Aquí vemos cómo la divergencia en torno a la consideración del estatuto del

\footnotetext{
${ }^{4}$ Ofrezco una traducción al español: "El hombre que sufre y el hombre desgraciado o sometido a la miseria se han hecho ajenos a las relaciones amo-esclavo que constituyen, en comparación con su situación, un estatuto casi prometedor. El esclavo tiene la suerte de tener un amo; el amo es hoy en día eso a lo que está sirviendo, mañana será eso contra lo que podría sublevarse. Hay esclavos sin amo, cuya esclavitud es tal que han perdido todo amo, toda relación con el amo, toda esperanza, por lo tanto, de liberación, como así también toda posibilidad de rebeldía. Cuando se ha perdido el amo, porque se ha vuelto sin nombre, un puro poder irresponsable, inencontrable, ya la situación es extremadamente dificil, pero las potencias abstractas aún pueden ser nombradas, la más lejana y la más inasible se llama un día Dios, y la omnipotencia de Dios finaliza permitiendo un combate decisivo. Mucho más grave es la esclavitud que es la ausencia del esclavo, la servidumbre de las sombras, ella misma aparentemente tan ligera como una sombra, cuando el destino carece de peso y de realidad. Me rebelo, luego somos, dijo Albert Camus en unas palabras donde puso toda la decisión de una esperanza solidaria. Pero aquel que ha perdido el poder de decir 'Yo' está excluido de esta palabra y de esta esperanza'.
} 


\section{Noelia Billi}

"desgraciado" se replica en una diferencia fundamental en torno a la concepción de la comunidad. Para Camus, esta se entiende a modo de reunión de muchos individuos que rompen con su aislamiento debido a un fin común, haciendo indispensable el pasaje del desgraciado a la primera persona que se afirma (primero en singular y luego en plural). Sin embargo, de acuerdo con Blanchot, la comunidad es una dimensión en la que lo único común es la desposesión de sí y no el autoaferramiento, el roce con el otro que impide que me conozca y que lo conozca, que me capture y lo capture (volveremos a esto más adelante). De allí que, blanchotianamente, el desgraciado sea una figura de lo impersonal, insoportable si se quiere, pero que no puede ser reconducida a la primera persona: ni bajo el modo del individuo ni bajo el del colectivo unificado por algo en común (un rasgo de clase, un fin, un origen, etcétera).

Así pues, la mayor objeción a la rebelión camusiana está en el mismo punto que provoca el rechazo de Sísifo: Camus busca una rebeldía que tenga un punto de partida, un origen, un principio, y lo encuentra en la negación que se planta ante el absurdo con las armas de la lógica y le espeta un "No" que, rápidamente, se recicla como fuerza de hacer mundo y poder sobre este. Esta estrategia tiene dos dificultades para Blanchot: por una parte, enrolarse en las filas del pensamiento lógico es considerado como una suerte de recaída en un fundamento subjetivo de la acción: si bien la lógica supone la universalidad (toda vez que su verdad se verificaría en la independencia respecto del individuo que opera de acuerdo con ella), esta no equivale a lo impersonal que Blanchot reivindicará, porque la lógica supone aceptar la igualdad de los hombres en este sentido, es decir, aceptar los principios de la Ilustración, lo que implica la inclusión en un marco de taxonomías y jerarquizaciones que, en nuestro tiempo, se declinan como un humanismo. He aquí la segunda dificultad: este uso de la lógica se evidencia humanista en la medida en que se la pone al servicio de un nuevo intento de dominio sobre el mundo, una suerte de inversión de los lugares de poder que no altera la esencia de la definición de lo humano que ha conducido al problema de la desgracia en primer lugar: la obsesión por la apropiación de todo lo otro, su reducción a la identidad de lo mismo. Desde esta perspectiva, Blanchot podrá afirmar que se desvirtúa la potencia de Sísifo al transformarlo en la figura de la impotencia; hay que hacer el esfuerzo por ver lo que Camus no pudo, a saber: la resistencia de Sísifo reside en su rechazo (neutro) al poder, en un no-poder que en lugar de impedirle la acción en el mundo lo lanza a él sin obligarlo a someterse a fines o razones.

\section{SÍSIFO EN EL INFIERNO}

¿Quién es Sísifo? ¿Cuál es su morada? Se recordará que cuando Camus leía este antiguo relato griego, en 1942, encontraba allí una heroicidad trágica sostenida en la lucidez de Sísifo respecto de su condición, lo que era propicio para tomarlo como modelo de la lucha por la liberación de los oprimidos en un mundo desencantado: 
Si ce mythe est tragique, c'est que son héros est conscient. Où serait en effet sa peine, si à chaque pas l'espoir de réussir le soutenait? L'ouvrier d'aujourd'hui travaille, tous les jours de sa vie, aux mêmes tâches et ce destin n'est pas moins absurde. Mais il n'est tragique qu'aux rares moments où il devient conscient. Sisyphe, prolétaire des dieux, impuissant et révolté, connaît toute l'étendue de sa misérable condition : c'est à elle qu'il pense pendant sa descente. La clairvoyance qui devait faire son tourment consomme du même coup sa victoire. Il n'est pas de destin qui ne se surmonte par le mépris. ${ }^{5}$ (Camus, 1942, p. 116)

Camus deposita la carga de la victoria de Sísifo en la capacidad de no dejarse someter por la lógica absurda de su tarea, una lógica que implica el recomienzo de "un esfuerzo que no terminará nunca", pero que no excluye, no obstante, la humana actividad de autocreación de un destino personal sostenido en los pilares de la memoria, la imaginación y la muerte propia (Camus, 1942, p. 118). En el mundo sin sentidos extrahumanos que Camus pone como escenario de Sísifo - un "espacio sin cielo" y un "tiempo sin profundidad" (p. 115)-, lo único que resuena es un "si'" que parece evocar el zaratustriano “¿Era esto la vida? ¡Bien! ¡Otra vez!” (Nietzsche, 2009, p. 225)

¿Pero acaso Sísifo no había muerto? Camus indica que a su héroe le ha sido asignado el infierno como escenario de su tarea, aunque también podría pensarse que el carácter infernal está dado por ese inacabamiento eterno de la tarea que le ha sido encomendada: en rigor, el autor de L'Étranger equipara aquel infierno perdurable con el mundo sin dioses, dejando que se deslice allí una finísima grieta que Blanchot sabrá explotar. Se trata de la cuestión de la muerte, de la función que esta cumple en el imaginario camusiano que, finalmente, termina por oponer el "Sí" de Sísifo al "No" del rebelde.

Como recuerda Blanchot, las lecturas de los comentaristas de mediados del siglo XX ponían la muerte en el centro de las problemáticas que Camus planteaba. En

\footnotetext{
${ }^{5}$ Ofrezco una versión en español: "Si este mito es trágico lo es porque su héroe es consciente. ¿En qué consistiría, en efecto, su castigo si a cada paso la esperanza de conseguir su propósito lo sostuviera? El obrero actual trabaja, todos los días de su vida, en las mismas tareas y ese destino no es menos absurdo. Pero no es trágico sino en los raros momentos en que se hace consciente. Sísifo, proletario de los dioses, impotente y rebelde, conoce toda la extensión de su miserable condición: en ella piensa durante su descenso. La clarividencia que debía constituir su tormento consuma al mismo tiempo su victoria. No hay destino que no se venza con el desprecio".

${ }^{6}$ Vale recordar que en L'homme revolté Camus dedica un apartado a Nietzsche ('Nietzsche et le nihilisme", Camus, 1951, p. 88-115), donde reconoce el progreso que su pensamiento supone respecto de la evolución hacia un modo de rebeldía que prescinda de los consuelos trascendentes (sobre todo, de Dios). Sin embargo, lee en el filósofo alemán una arrolladora máquina de decir "s's" que resulta incapaz, en última instancia, de decir "no" a la injusticia terrena (el amor fati leído de manera 'fatalista'). Ello supone hacer de Nietzsche el pensador de la voluntad de poder individual que terminaría por suscribir una voluntad de poder totalitaria, inscribiéndolo así en un "cesarismo biológico" que lleva como eco un "cesarismo histórico" cuya figura sería el marxismo-leninismo. De esta manera, vemos que Nietzsche es leído como defensor de un individualismo determinista, una lectura bastante alejada de la que Blanchot realiza. Una manera de leer el diferendo entre Blanchot y Camus es hacerlo surgir de una recepción dispar de las voces que habitan la obra nietzscheana: una ligada a lo impersonal por la vía de lo fragmentario en el primer caso, y otra asociada al anarcoindividualismo en el segundo.
} 


\section{Noelia Billi}

sus novelas, la muerte se daba de un pistoletazo, abrumado por el sol; o acontecía la muerte de la madre, que generaba el eco de una gota de agua cayendo en la oquedad del alma humana (L'Étranger); o bien el asesinato político era perpetrado en nombre de la revolución (Les justes). Pero además, Camus consideraba en sus ensayos (que funcionaron como "explicación" y justificación de aquellas obras) que el suicidio era el único problema filosófico verdaderamente serio (habida cuenta del acto fundamental al que obligaría su "resolución") (Camus, 1942, p. 18-23) y, años más tarde, caracterizaría la época actual como aquella en la que el asesinato era lógicamente fundado o producto de un razonamiento que lo ponía al servicio de la historia (Camus, 1951, p. 13-22). Y si bien la sensibilidad absurda termina rechazando tanto el suicidio como el asesinato, el propio Camus es quien distancia la posición de su Sísifo de la del rebelde, toda vez que el primero era el hijo de un mero "sentimiento", una "emoción desesperada" (p. 21), incapaz de otro movimiento que no fuera el de la sola pervivencia sin capacidad de crear, mientras que el rebelde es el producto de la evidencia de la injusticia. Es decir, que mientras Sísifo es la figura de un absurdo que, como un fuego fatuo, brilla sin iluminar un camino por medio del abigarrado conjunto de hechos sinsentido que es el mundo, por su parte el hombre rebelde se yergue sobre el caos para imponerle orden y concierto o, al menos, para limitar sus derivas azarosas y encauzar las energías hacia un mundo más "humano". En este sentido, mientras Sísifo es quien rechaza el suicidio (darse muerte) porque estar vivo sin razón es la única evidencia a la que llega siguiendo una lógica individual, para Camus el rebelde (cuyo odio a la muerte lo hace transformador por definición) se encuentra históricamente instalado en situaciones de amo-esclavo y debe en cada caso decidir entre matar o morir, siguiendo una lógica que, en determinados estadios, es capaz de justificar el asesinato. Si bien el razonamiento rebelde terminará en la imposibilidad de justificar la muerte (de allí que quien se vea llevado a matar por "buenas" razones deba inexorablemente aceptar a la vez su muerte como "castigo", como se describe en Les justes y se explica en L'Homme revolté $)$, la distancia entre Sísifo y el rebelde consumado en torno a la muerte es bien

\footnotetext{
7 'Il est donc possible de dire que la révolte, quand elle débouche sur la destruction, est illogique. Réclamant l'unité de la condition humaine, elle est force de vie, non de mort. Sa logique profonde n'est pas celle de la destruction; elle est celle de la création. Son mouvement, pour rester authentique, ne doit abandonner derrière lui aucun des termes de la contradiction qui le soutient. Il doit être fidèle au oui quil contient en même temps qu'à ce non que les interprétations nihilistes isolent dans la révolte. La logique du révolté est de vouloir servir la justice pour ne pas ajouter à linjustice de la condition, de s'efforcer au langage clair pour ne pas épaissir le mensonge universel et de parier, face à la douleur des hommes, pour le bonheur. La passion nihiliste, ajoutant à linjustice et au mensonge, détruit dans sa rage son exigence ancienne et s'enlève ainsi les raisons les plus claires de sa révolte. Elle tue, folle de sentir que ce monde est livré à la mort. La conséquence de la révolte, au contraire, est de refuser sa légitimation au meurtre puisque, dans son principe, elle est protestation contre la mort.". (Camus, 1951, p. 352). Ofrezco una versión en español: "Por lo tanto, es posible decir que la rebelión, cuando desemboca en la destrucción, es ilógica. Al reclamar la unidad de la condición humana es fuerza de vida, no de muerte. Su lógica profunda no es la de la destrucción, sino la de la creación. Para que su movimiento siga siendo auténtico no debe abandonar tras de sí ninguno de los términos de la contradicción que lo sostiene. Debe ser fiel al sí que contiene al mismo tiempo que a ese no que las interpretaciones
} 
clara: para el primero, el problema pasa por la propia muerte, para el segundo, por la responsabilidad por la muerte de cualquier hombre.

\section{EL DERECHO A LA MUERTE (DE SÍSIFO)}

Blanchot muestra los meandros del camino que lleva a Camus a deponer a Sísifo para que se yerga el hombre rebelde. Y sus meditaciones apuntan a la legitimidad profunda del tan mentado "derecho a la muerte" que sería lo propio del hombre, locus donde el absurdo camusiano se revela como un nuevo episodio del humanismo occidental que históricamente deposita allí la especificidad de la vida humana en contraposición al resto de lo existente.

La reflexión blanchotiana destacará a Sísifo porque es allí donde se encuentra la pérdida reiterada que marca los mil crepúsculos que destejen lo humano y lo exponen a un afuera donde lo acosa lo imposible.

Que nous dit Sisyphe? Non point qu'il ne veut pas se donner la mort, mais qu'il ne veut pas parce qu'il ne le peut pas : il a précisément quitté l'espace de la possibilité, ayant quitté le monde où mourir est possible. (Blanchot, 1969, p. 267) ${ }^{8}$.

Este es el sitio donde la impotencia no se prefigura como el punto cero desde donde un Hombre podría desarrollarse, sino como la imposibilidad insuperable que impide la totalización de un mundo, la consecución de un continuo donde el humano podría atribuirse la creación de un todo. Perdido el "derecho a la muerte" se ingresa al espacio del no origen, donde las formas humanas no se distinguen cualitativamente de otras formas sino que se mezclan con ellas, incapaces de cerrarse en una interioridad pura. Con el fin de captar la sutileza que indica Blanchot, debe advertirse la diferencia en la localización del desgraciado Sísifo que ambos autores plantean. Si para Camus es el punto cero, la nada humana que, al no recostarse en una trascendencia, será capaz de atribuir a sus propias fuerzas la creación de un mundo habitable (su "Sí"), para Blanchot, en cambio, no es así. En este segundo caso, Sísifo no es figurado como el límite impuesto a la avanzada de la muerte ni como el lugar hueco de la nada: es

nihilistas aíslan en la rebelión. La lógica del rebelde consiste en querer servir a la justicia para no aumentar la injusticia de la situación; en esforzarse por emplear un lenguaje claro para no espesar la mentira universal, y en apostar, frente al dolor de los hombres, por la felicidad. La pasión nihilista, al aumentar la injusticia y la mentira, destruye en su furor su exigencia antigua y se despoja así de las razones más claras de su rebelión. Mata, enloquecida al sentir que este mundo está entregado a la muerte. La consecuencia de la rebelión, por el contrario, consiste en negar su justificación al asesinato, puesto que, en su principio, es protesta contra la muerte". Asimismo, Camus reitera su conclusión en "Les pharisiens de la justice" al responder a la revista Caliban acerca del problema que anima Les Justes: "1ํㅣ y a des limites. Les enfants sont une limite (il en est d'autres); $2^{\circ}$ On peut tuer le gardien, exceptionnellement, au nom de la justice ; $3^{\circ}$ Mais il faut accepter de mourir soi-même" (Camus, 1953, p. 21). Ofrezco una versión en español: " $1{ }^{\circ}$ Hay límites. Los niños son un límite (hay otros). $2^{\circ}$ Se puede matar al carcelero, excepcionalmente, en nombre de la justicia. $3^{\circ}$ Pero es preciso aceptar la propia muerte".

${ }^{8}$ En español: “¿Qué nos dice Sísifo? No que no quiere matarse, sino que no quiere porque no puede: precisamente ha abandonado el espacio de la posibilidad al abandonar el mundo donde es posible morir". 


\section{Noelia Billi}

"l'image de cet entre-deux où l'on n'appartient ni à l'une ni à l'autre rive" (Blanchot, 1969 , p. 268) ${ }^{9}$. Ni comienzo ni meta por fin lograda, Sísifo es puro andar indeciso cuya afirmación es radical no porque diga "Sí" a un principio donde se arraigue sino porque constata que hay algo, un perpetuo movimiento al que se entrega haciéndose piedra que rueda.

Étrange Oui qui enlève seulement au Non sa pureté de négation, Oui qui n'affirme rien, étant le flux et le reflux de l'indécision à partir de quoi rien ne commence, mai tout recommence sans commencement ni fin, Oui qui nos ôte jusqu'à la certitude du néant et est comme le noyau secret du Non (p. 268) ${ }^{10}$.

Para Blanchot, esto dibuja el contorno del absurdo en su forma neutra: la imposibilidad de erguir una pared (un punto cero) lo suficientemente firme como para apoyar sobre ella la piedra (basal) y que el tiempo infinito deje de rolar, una pared que sirva para impulsarse o parapetarse. Sísifo habita el Afuera del mundo, que es un umbral donde solo hay relación con lo inhumano, con la piedra; Sísifo es la hoja vegetal que vive fuera de sí, cuya única fuerza se invierte en afirmar esta exterioridad sin fin y sin comienzo. Sísifo no tiene amo porque ni siquiera se tiene a sí mismo: él habita el único infierno que un ateo podría tolerar, aquel que ha sido el margen de la creación divina (y no el lugar de reconversión de los injustos), aquel submundo donde $\sin$ Dios y sin ley, ya no subsiste siquiera la posibilidad de matarse porque la muerte ya ha acaecido.

Como señalábamos antes, Sísifo no podría devenir esclavo porque, perdido el mundo, él ha perdido a su vez el derecho a la muerte, enrareciendo así la posibilidad de un devenir humano. Por ello Blanchot enfatiza el intervalo que separa al héroe trágico del rebelde (metafísico o revolucionario), y en tal énfasis debe leerse aquella hipótesis acerca de la comunidad de la desgracia que mencionábamos más arriba. A diferencia de Camus - para quien el derecho a la muerte acomuna a los humanos como a una "especie", haciendo de esta el telos de una comunidad libre y justa-, desde la perspectiva blanchotiana la desgracia es la quintaesencia de la impotencia, lo que quita al desgraciado la posibilidad de decir "yo" y de reunirse con sus "iguales". No por ello dejará de postularse una comunidad, pero ya no será la fraternal unión entre iguales, entre hombres, sino ese vivir-juntos donde antes que rasgos o trazos idénticos a compartir, prima la exposición, la vida liminar que excede la individuación y sobrevive a la muerte propia ${ }^{11}$.

\footnotetext{
${ }^{9}$ En español: "la imagen de aquel entre donde no se pertenece ni a una orilla ni a la otra".

${ }^{10}$ Ofrezco una versión en español: "Extraño Sí que solo le quita al No su pureza de negación. Sí que no afirma nada, que es el flujo y el reflujo de la indecisión a partir de lo que nada comienza, sino que todo recomienza sin comienzo ni fin, Sí que nos quita hasta la certeza de la nada y es como el núcleo secreto del No".

${ }^{11}$ Blanchot ha discurrido largamente sobre la cuestión de la "comunidad de los que no tienen nada en común" (y porque no tienen nada en común más que su común exposición a lo otro) en La communauté inavouable (Blanchot, 1983). Dicho libro retoma los problemas planteados por la comunidad negativa postulada por Bataille en tomo al grupo Acéphale, luego por los eventos de mayo de 1968 en Francia (en los que Blanchot tuvo un lugar muy activo en 
En tanto comunidad de exposición, uno de los trazos que emerge del pensamiento blanchotiano supone el rechazo a reducir la muerte a prerrogativa humana. Si bien esto puede sonar extraño (sin dudas todo lo que vive puede morir), no debe olvidarse la enorme presión que acerca del concepto de muerte ejerce la filosofía, por lo menos desde la filosofia hegeliana (inspiración, precisamente, de la dupla amo-esclavo que articula aquí la posición camusiana) $)^{12}$. Hegel se fuerza por establecer que el hombre se separa del resto de los animales afirmando soberanamente su "derecho a morir", que se traduce como el poner en riesgo su vida a los fines de adquirir un dominio más acabado sobre sí mismo y sobre los otros ${ }^{13}$. De este enlace entre muerte y soberanía se derivan los distintos modelos de comunidad de la teoría política moderna, y sobre todo el léxico que liga la política a distintos modelos de la soberanía y el sujeto (individual o colectivo) (Fistetti, 2004). De aquí se desprende la importancia que adquiere la noción de morir (que desplaza a la de muerte) en Blanchot en cuanto se asocia a lo impersonal, porque así enfatiza el carácter inapropiable y desapropiador de la muerte: ya no el punto de sutura que da sentido final a la propia vida, sino el punto de fuga irreversible que dejará por siempre abierta (y como en una especie de limbo de reiteración infinita) a la serie de acontecimientos que conforman una vida.

los comités de estudiantes y escritores), para finalizar en una redefinición de lo común a partir de la exposición tal como se verifica en la novela La maladie de la mort de Marguerite Duras, cuya protagonista plantea una resistencia inclaudicable a la apropiación no a partir del cierre sobre sí sino del rechazo a las figuras de lo personal (cuya resistencia a la apropiación de sí minan todo posible dominio de los otros). Es conocido el debate que este texto blanchotiano (que es, de hecho, un modo de lectura de la cuestión de la comunidad tal como había sido pensada por Jean-Luc Nancy poco tiempo antes) originó en Francia e Italia (Nancy, 1986, 2001, 2014; Agamben, 2001; Esposito, 1998). Sobre las derivas del tema en el pensamiento político de Blanchot, ver Iyer (2004). Aquí abordamos el problema político pero a partir de la figura de lo impersonal que supone para Blanchot el "desgraciado". Con ello, apuntamos a eludir la reconducción (casi sistemática para el pensamiento contemporáneo) de la cuestión política a las categorías de la teoría política moderna (Estado, Soberanía, Sociedad Civil, Representación), pues entendemos que en Blanchot es posible encontrar modos de lo común que exceden los marcos que los conceptos antes mencionados ofrecen para pensar el vivir-juntos.

${ }^{12}$ Por supuesto, desde antes también, pero lo limitaremos al sistema de Hegel con el fin de cernir los contomos de un planteo moderno de la muerte que marca el lugar preciso en que el sujeto moderno emerge. Es quizás Heidegger quien muestra las consecuencias últimas de plantear la muerte como algo puramente humano (recordemos que, según el filósofo, solo el Dasein es capaz de morir, el resto de los vivientes cesan, terminan o "la palman" (Heidegger, 1927, p. 46-53). En efecto, desde antiguo los pensadores toman como punto de partida la "conciencia de la muerte" como rasgo antropogénico, es decir, como iluminación que de una sola vez separa al hombre del resto de los animales y lo pone en carrera hacia una humanización cada vez más completa. A esta separación y derrotero, Occidente los nombra "cultura". A este respecto, la humanización estará dada por un dominio más organizado y sistemático de las posibilidades propias en tanto el hombre se concibe a sí mismo como "ser de cultura" que debe darse un mundo (que, por falta de "naturaleza", no le viene dado). Sobre este punto, en particular en la tradición filosófica alemana ver Gehlen (1961).

${ }^{13} \mathrm{El}$ "derecho a la muerte" como impronta hegeliana que marca el rumbo del pensamiento moderno y contemporáneo, es analizado en detalle por Blanchot (1949) en "La littérature et le droit à la mort" (p. 293-331), con especial énfasis en las consecuencias de ello en el entrelazamiento de muerte y lenguaje. 


\section{Noelia Billi}

Es de acuerdo con esta interpretación que se puede aseverar, pues, que Sísifo adquiere los contornos del cazador Gracchus kafkiano: a semejanza de él (que "por error" no pudo morir), continúa en la tierra de un modo ni vivo ni muerto, póstumo a su muerte, que resultó del todo insignificante (Kafka, 2000). En efecto, en ambos relatos la muerte es un estado suspendido (el tono "fortuito" se incrementa en el caso de Kafka, que ya no hace depender dicho acontecimiento de un "castigo" como sí sucede en el relato de Sísifo) que no se encamina a ninguna resolución, redención o acabamiento. Tanto la figura trágica como Gracchus indican, para Blanchot, las grietas que perturban la "tarea de la cultura": la de "devolverle a la muerte una especie de pureza [...]. Hacerla auténtica, personal, propia, o bien hacerla posible" (Blanchot, 1969, p. 269270). He aquí la síntesis blanchotiana de los motivos por los cuales se insiste en aquel morir que implica una muerte ya acontecida pero bajo el modo del suspenso y nunca del acabamiento: en tanto se mida la muerte con la vara de lo personal, con el criterio de la autenticidad o de acuerdo con los efectos de dominio que es capaz de generar, se tratará de una idea de la muerte (y por eso de un hecho requerido por la cultura comprendida como el proceso de humanización del hombre) o, dicho de otro modo, de un intento de purificarla (de hacerla puramente humana).

Leída desde dicha matriz posthumanista que Blanchot avanza, se vuelve legible la necesidad de Camus de hacer desaparecer a este Sísifo que no podría morir, como le sucede a Gracchus, ya después de muerto. Comprometido con la tarea edificante de una especie humana, Camus repudiará su propia creación al reemplazarla con figuras que ya no se encuentren sometidas a la repetición, con hombres rebeldes capaces de administrar la muerte (la propia y la ajena).

Esto es lo que llama la atención a Blanchot, el interés camusiano por poner tras de sí la tragedia de Sísifo, que es también la situación desesperada de los nihilistas rusos (Kaliaev y compañía): han entrado al espacio de la muerte por un lugar de no poder, han muerto o han matado y no hay lógica o valor que justifique ni la vida ni la muerte. "Mourir courageusement, beaucoup d'hommes le peuvent; le courage est le compagnon que le monde nous envoie, l'énergie que la vie nous délègue pour faire de la mort un événement encore uni aux valeurs du monde et au respect de la vie" (Blanchot, 1969, p. 278) ${ }^{14}$.

Blanchot identifica este espacio del "no poder" con la palabra [parole], como aquello que abre el espacio del afuera en el que las posibilidades de significar o representar no son humanas, en el que la palabra que no es del hombre (que quisiera por su intermedio dominar el mundo) sino de la muerte misma, que comunica la separación, el intervalo que no puede ser ocupado por el mundo humano y por eso mismo permanece como lo inhumano en el hombre. Así pues, Blanchot indicaría que sin poder para morir, no hay en verdad poder para matar, y que Sísifo puede ser escondido pero

\footnotetext{
${ }^{14}$ Ofrezco una versión en español: "Morir valientemente, muchos hombres pueden hacerlo; la valentía es el compañero que nos envía el mundo, la energía que nos delega la vida para hacer de la muerte un acontecimiento todavía unido a los valores del mundo y al respeto de la vida".
} 
no superado: podemos hacernos la ilusión de estar vivos y de esperar la muerte que venga a cerrar nuestra insignificante existencia con una negra corona, pero la roca no se biodegrada sino que dispersa cada vez las esquirlas de la muerte, engrosando el espacio que media entre el ser y la nada: "grouillement d'inexistence, prolifération sans réalité, vermine du nihilisme: nous-mêmes." (Blanchot, 1969, p. 268)

\section{CONCLUSIONES}

Para finalizar este trabajo, recapitularé algunas de las conclusiones parciales que se desprenden de lo analizado. Por una parte, hemos recorrido la lectura que Blanchot realiza de la progresión del pensamiento de Albert Camus, que va de un Sísifo absurdo hacia una rebelión del hombre desgraciado reconvertido a sujeto colectivo (nosotros) que actúa en el mundo. Hemos observado que Blanchot atribuye el abandono del héroe trágico por parte de Camus a una comprensión sesgada del absurdo que dicha figura involucra: mientras para Camus Sísifo traduce la impotencia que abreva en las aguas de la individualidad, desde la perspectiva blanchotiana, su absurdo movimiento reiterativo es neutro en la medida en que nada en lo impersonal sin plantearlo como un estadio a superar. Así, Blanchot muestra la potencia del particular no-poder de Sísifo, que lo transforma en paradigma de la resistencia posthumana en la medida en que se revela como lugar inhumano e inapropiable, punta de lanza de un modo de vivir-juntos (comunidad) que no se basa en la dominación y en la administración de la muerte (como sucede en el caso del rebelde camusiano), sino en la común exposición al otro.

Con la comunidad de exposición nos hallamos en el seno de una de las líneas que la filosofia contemporánea explora en torno a modos de lo común que no se apuntalen en ni busquen reinstaurar una metafísica del sujeto (individual o colectivo), a saber: la resistencia de lo neutro a modo de ejercicio de desplazamiento del antropocentrismo imperante en nuestra tradición. En efecto, en las notas que aquí destacamos del análisis blanchotiano, se puede observar con mayor rigor cuál es la fisura política en la que un pensamiento de lo neutro se traduce como resistencia y persistencia de cierta materialidad (las condiciones desgraciadas del mundo en que se vive y se muere, la afirmación constante del seguir andando en ausencia de metas, la prescindencia de las armas del dominio para dicha afirmación) que rechaza ser negada bajo las formas de una racionalidad que, eventualmente, despoja al mundo de todo sentido que no sea exclusivamente humano. Sísifo como compañero de la piedra, Sísifo como esquirla de materia viviente moviéndose en círculos entre la vida y la muerte, hace signos hacia una comprensión de lo que existe que nos fuerza a considerar y valorar los aspectos inhumanos de lo que hay ya no como amenazas permanentes al imperio del hombre sino como ocasión de circular por el mundo sin intentar apropiárselo.

\footnotetext{
${ }^{15}$ En español: “[H]ormigueo de inexistencia, proliferación sin realidad, plaga del nihilismo: nosotros mismos”.
} 
Universidad de Buenos Aires* Puan 480, Ciudad Autónoma de Buenos Aires (Argentina) milcrepusculos@gmail.com

\section{OBRAS CITADAS}

Agamben, Giorgio. (2001). La comunità che viene. Torino: Bollati Boringhieri.

Asensi Pérez, Manuel. (2006). Los años salvajes de la teoría: Ph. Sollers, Tel Quel, y la génesis del pensamiento post-estructural francés. Valencia: Tirant Lo Blanch.

Berstein, Serge y Pierre Milza. (1991). Histoire de la France au 20e siècle. París: Complexe.

Blanchot, Maurice. (1983). La communauté inavouable. Paris: Minuit.

— (1969). L'Entretien infini. París: Gallimard.

_ (1949). La part du feu. París: Gallimard.

_ (1943). Faux pas. Paris: Gallimard.

Camus, Albert. (1953). Actuelles II (Chroniques 1948-1953). Paris: Gallimard.

— (1951). L'Homme révolté. París: Gallimard.

— (1942). Le Mythe de Sisyphe. Paris: Gallimard.

Esposito, Roberto. (1998). Communitas: origine e destino della comunità. Torino: Einaudi.

Fistetti, Francesco. (2004). Comunidad. Léxico de Política. Trad. H. Cardoso. Buenos Aires: Nueva Visión.

Gehlen, Arnold. (1961). Anthropologische Forschung. Reinbek: Rowohlt.

Heidegger, Martin. (1927). Sein und Zeit. Halle: Max Niemeyer Verlag.

Iyer, Lars. (2004). Blanchot's Communism: Art, Philosophy and the Political. Londres: Palgrave Macmillan UK.

Kafka, Franz. (2000). "El cazador Gracchus", en Kafka, Franz. Cuentos completos. Trad. J. R. Hernández Arias. Madrid: Valdemar, 231-234.

Nancy, Jean-Luc. (2014). La Communauté désavouée. París: Galilée.

- (2001). La communauté affrontée. Paris: Galilée, (1986). La communauté désoeuvrée. París: Christian Bourgois.

Nietzsche, Friedrich. (2009). Así habló Zaratustra. Trad. A. Sánchez Pascual. Madrid: Alianza.

Ory, Pascal y Jean-François Sirinelli. (2004). Les Intellectuels en France de l'Affaire Dreyfus à nos jours. Paris: Perrin.

Poster, Mark. (1975). Existential Marxism in Postwar France. From Sartre to Althusser. Princeton: Princeton University Press.

Sartre, Jean-Paul. (1983). Cahiers pour une morale. París: Gallimard.

— (1947). Situations 1. Paris: Gallimard.

Winock, Michel. (2006). La Gauche en France. Paris: Perrin. 